\title{
The Mull Hypothesis: is cannabis use contributing to high tobacco use prevalence among young North Coast males?
}

\section{Eric K. van Beurden ${ }^{\mathrm{A}}$, Avigdor Zask ${ }^{\mathrm{A}}$, Megan Passey ${ }^{\mathrm{B}}$ and Annie M. Kia ${ }^{\mathrm{A}}$}

${ }^{\mathrm{A} N o r t h}$ Coast Health Promotion, Population Health, Planning and Performance Directorate, North Coast Area Health Service

${ }^{\mathrm{B} D e p a r t m e n t}$ of Rural Health (Northern Rivers), University of Sydney and North Coast Area Health Service

${ }^{\mathrm{C} C o r r e s p o n d i n g ~ a u t h o r . a v i g d o r . z a s k @ n c a h s . h e a l t h . n s w . g o v . a u ~}$

\begin{abstract}
Men aged 25-34 years, in North Coast NSW, have higher documented smoking rates than elsewhere in the state. The present paper explores potential causes of elevated smoking rates in this population and proposes that tobacco dependence resulting from 'mulling' (mixing) cannabis with tobacco may be contributing.
\end{abstract}

Young people can become dependent on tobacco by initially mixing it with cannabis. ${ }^{1-3}$ This 'reverse gateway' process is contrary to the theory that tobacco use precedes cannabis use. ${ }^{4}$ The present paper proposes that the high smoking prevalence documented in North Coast men aged 25-34 years may reflect this. These rates are higher than for other rural areas and New South Wales (NSW) in general (Figure 1). ${ }^{5}$ They are also higher than rates in women and these trends are consistent over time. ${ }^{5} \mathrm{NSW}$ Health Survey sample sizes are primarily designed for population health indicators monitored at an area health service level. Analysing the survey data for a small subgroup, such as an age group within one gender, has an inherent weakness due to inadequate sample size. Despite this, the difference in 2004 reached significance (Table 1). Although the data are not presented here, a similar trend is evident among men 35-44 years old.

\section{Possible causes of high smoking rates}

Four possible causes are considered in the light of available evidence. First, it may be a statistical aberration due to the small size of the cohort samples in the Health Survey. Rates for men aged 25-34 years (1998 and 2002 to 2005) are based on 70-200 respondents. ${ }^{5}$ However, this is an unlikely cause of a trend that is consistent over time.
Second, the high rates may be reflective of the North Coast Area Health Service (NCAHS) being the most socioeconomically disadvantaged area in NSW with the highest combined unemployment-sickness-disability benefit recipient rate. ${ }^{6-8}$ Low socio-economic status is a potential contributor; however, it is unclear why this would not also cause an elevation in smoking rates in women.

Third, and linked to socio-economic status, is the fact that the NCAHS has the second highest proportion of Aboriginal residents of all the area health services in NSW (3.6\%). ${ }^{9}$ Evidence suggests that more Aboriginal people smoke than non-Aboriginal people do. ${ }^{7,9}$ However, high smoking rates in $3.6 \%$ of the population (as opposed to $1.9 \%$ of the NSW population) would only contribute another $1-2 \%$, with little effect on the rate for all young men.

\section{The Mull Hypothesis}

The fourth considered cause is that many young men become dependent on tobacco through the 'reverse gateway' process. ${ }^{1}$ Subsequently, long-term cannabis users find it difficult to quit smoking tobacco because of the reinforcing influence of their cannabis use. ${ }^{3}$ Furthermore, cannabis use is at its highest in this male age group, at double the female rates. ${ }^{7}$ Thus, while there has been a general reduction in smoking over the last decade, this trend may have been attenuated in the North Coast because of the many cannabis users who were unable to quit using tobacco.

Since the 1970s, the North Coast alternative lifestyle movement has normalised cannabis use. ${ }^{10}$ Although data

Table 1. Comparison of the prevalence, with $95 \%$ confidence intervals, for smoking in 25-34 year old North Coast males with populations for NSW and two other rural Area Health Services in 2004.

\begin{tabular}{lcc}
\hline Population Group & $\begin{array}{c}\text { Prevalence } \\
\%\end{array}$ & $\begin{array}{c}95 \% \mathrm{Cl} \\
\%\end{array}$ \\
\hline NCAHS & 64.1 & $49.1-79.1$ \\
GSAHS & 34.3 & $19.1-49.6$ \\
GWAHS & 39.0 & $26.2-51.8$ \\
NSW & 29.8 & $24.1-35.5$ \\
\hline NCAHS: North Coast Area Health Service; GSAHS: Greater Southern \\
Area Health Service; GWAHS: Greater Western Area Health Service.
\end{tabular}



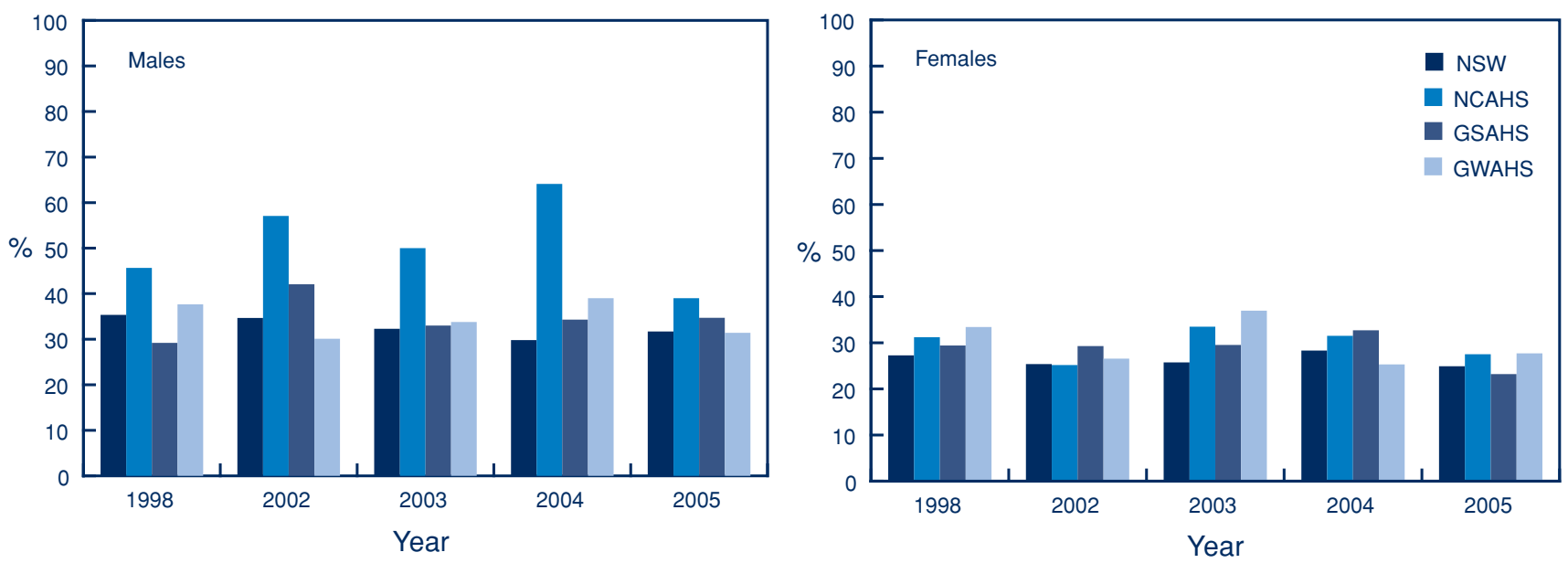

Fig. 1. Comparison of the prevalence (\%) of current tobacco smoking for 25-34 year old North Coast males and females with populations for NSW and two other rural Area Health Services for the period 1998-2005.

Source: NSW Health Survey. ${ }^{5}$ NCAHS: North Coast Area Health Service; GSAHS: Greater Southern Area Health Service; GWAHS: Greater Western Area Health Service.

were not available on rates of cannabis use in NCAHS compared with the rest of NSW, crime statistics suggest that cannabis use is higher; convictions for cultivation, use, possession and related crime incidents are the highest in NSW. ${ }^{10-14}$

During the 2006 National Cannabis Strategy consultations representatives from the North Coast cannabis-using community expressed concern that young users were becoming tobacco dependent due to 'mulling up'. The Mull Hypothesis may therefore explain part of excess tobacco use in young men on the North Coast, and has implications for tobacco control wherever young people experiment with use of cannabis.

\section{Investigating the trend}

The documented smoking rates for young North Coast men could be validated by larger sampling by the Health Survey or through advanced analysis of repeated trend data. Additional questions might clarify the prevalence of cannabis use and 'mulling', and whether people who do not smoke tobacco other than in their cannabis mix identify as tobacco smokers. Complementary data sources could also be explored.

\section{Conclusion}

To develop harm reduction strategies, interactions between onset and frequency of tobacco and cannabis use and the associated socio-economic factors need clarification, as does the nexus of reasons, circumstances and meanings of use.

\section{Acknowledgments}

We wish to thank Therese Dunn for data analysis, Reyna Dight, David Reilly and Gerry Williams for expert advice and Geoff Morgan for constructive comments.

\section{References}

1. Patton GC, Coffey C, Carlin JB, Sawyer SM, Lynskey M. Reverse gateways? Frequent cannabis use as a predictor of tobacco initiation and nicotine dependence. Addiction 2005; 100(10): 1518-25. doi:10.1111/j.1360-0443.2005.01220.x

2. Humfleet GL, Haas AL. Is marijuana use becoming a 'gateway' to nicotine dependence? Addiction 2004; 99: 5-6. doi:10.1111/j.1360-0443.2004.00596.x

3. Amos A, Wiltshire S, Bostock Y, Haw S, McNeill A. 'You can't go without a fag... you need it for your hash' - a qualitative exploration of smoking, cannabis and young people. Addiction 2004; 99(1): 77-81. doi:10.1111/j.13600443.2004.00531.x

4. Kandel DB, Yamaguchi K, Chen K. Stages of progression in drug involvement from adolescence to adulthood: Further evidence for the gateway theory. J Stud Alcohol 1992; 53 : $447-57$.

5. Population Health Division. The health of the people of New South Wales: Report of the Chief Health Officer. Health-related behaviours smoking in adults. Sydney: NSW Department of Health, 2004.

6. Barbeau EM, Krieger N, Soobader M-J. Working class matters: Socioeconomic disadvantage, race/ethnicity, gender, and smoking in NHIS 2000. Am J Public Health 2004; 94(2): 269-78.

7. Australian Institute of Health \& Welfare. 2004 National drug strategy household survey: detailed findings. AIHW cat. no. PHE66. Canberra: AIHW (Drug Statistics Series No. 16), 2005.

8. Population Health Division. The health of the people of New South Wales: Report of the Chief Health Officer. Social determinants socioeconomic indices. Sydney: NSW Department of Health, 2004.

9. Population Health Division. The Health of the People of New South Wales: Report of the Chief Health Officer. Aboriginal and Torres Strait Islander peoples Indigenous population by local government area. Sydney: NSW Department of Health, 2004. 
10. Reilly D, Didcott P, Swift W, Hall W. Long-term cannabis use: characteristics of users in Australian rural area. Addiction 1998; 93(6): 837-46. doi:10.1046/j.1360-0443.1998. 9368375.x

11. Transport and Population Data Centre: NSW Department of Planning. NSW SLA Population Projections 2001-2031, 2004 Release: Detailed Data, Version 1.2. Sydney: NSW Department of Planning, 2004.
12. Helliwell D, Reilly D, Rippingale C. Establishing a drug and alcohol service in an Australian rural area. Drug Alcohol Rev 1992; 11: 371-8. doi:10.1080/09595239200185501

13. Major C. Deadlocked: The drug law debate in Australia - 90's style. Connexions 1994; 14: 8-16.

14. Moffatt S, Goh D, Fitzgerald J. New South Wales Recorded Crime Statistics 2004. Sydney: NSW Bureau of Crime Statistics and Research, 2005. 